\title{
Technology, Methodology and Intervention: Performing Nanoethics in Portugal
}

\author{
António Carvalho • João Arriscado Nunes
}

Received: 24 December 2012 / Accepted: 21 May 2013

(C) Springer Science+Business Media Dordrecht 2013

\begin{abstract}
During the last few decades we have witnessed a proliferation of exercises dealing with the public participation of citizens in various different dimensions of their societies, including issues of science and technology. On the one hand, these mechanisms provide more robust forms of public engagement with matters that were traditionally dealt with by experts; on the other hand, they raise concerns relating to their design, efficiency or potential for the empowerment of citizens. As part of the EC-funded project DEEPEN (Deepening Ethical Engagement and Participation in Emerging Nanotechnologies) a research team in Coimbra, Portugal, was put in charge of identifying the ethical and social "impacts" of emerging nanotechnologies, transforming the traditional focus groups through the incorporation of two methodological innovations: the Pedagogy of the Oppressed and the Theatre of the Oppressed. This article reflects on the outcomes and
\end{abstract}

A. Carvalho

Centre for Social Studies, University of Coimbra,

Apartado 3087,

3001-401 Coimbra, Portugal

A. Carvalho $(\square)$

Department of Sociology, Philosophy and Anthropology,

University of Exeter,

Amory Building, Rennes Drive,

EX4 4RJ Exeter, United Kingdom

e-mail: antoniomanuelcarvalho@gmail.com

\section{J. A. Nunes}

Centre for Social Studies and Faculty of Economics,

University of Coimbra,

Coimbra, Portugal

e-mail: JAN@ces.uc.pt complexities of the introduction of these two methodologies. Since the participants had little or no information on nanotechnologies, we reflect on the politics of these focus groups by exploring how issues of intervention, subjectivity, representation and agency were interconnected during this exercise of public participation in Science and Technology, analyzing the role of social sciences in developing nanoethics.

Keywords Focus groups · Pedagogy of the Oppressed . Theatre of the Oppressed · Performativity - Nanoethics in Portugal $\cdot$ Intervention

\section{Introduction}

During the last decades, numerous devices of public participation have been developed at a multiplicity of institutional levels. Their number, complexity and diversity of institutional and political contexts generated substantial academic interest.

The configurations of these procedures are diverse, including participatory budgeting, consensus conferences, citizen juries, deliberative events or focus groups. These mechanisms can be distinguished according to: their bureaucratic and institutional characteristics; the political projects they promote; their efficiency; implications on governance at local, regional and national scales; their "objects" (territory, environment, health, science); their potential for emancipation and inclusiveness; the relationship between lay people and experts; the links between participatory and representative democracy. These mechanisms 
can also raise issues of representation and dangers of manipulation and co-optation or even create pathologies in participants.

The above mentioned issues illustrate the political dimension of their design, the methodologies that are used, and the actions of facilitators or the formats for self-expression. This means that the role of those in charge of organizing such mechanisms is political their interventions are part of an assemblage that allows the emergence of participatory (and hopefully critical) subjectivities. Therefore, the aim of this article is, through the case study of public participation in nanotechnologies, to reflect on the productive dimension of social sciences' methods concerning the "politics" of participatory mechanisms related to nanotechnologies.

As part of the research project DEEPEN (Deepening Ethical Engagement and Participation in Emerging Nanotechnologies), funded by the European Commission, a research team in Coimbra, Portugal, set out to "identify" ethical and social concerns on nanotechnologies through participatory procedures in 2008. The researchers started out with a version of the classical focus group approach, but introduced two innovations: an explicit focus on a dialogical approach to knowledge production, drawing on Paulo Freire's Pedagogy of the Oppressed, and a performative stand on the enactment of political, social and ethical reflections, influenced by Augusto Boal's Theatre of the Oppressed. Participants were asked to develop performances illustrating matters of concern [20] to them on nanotechnologies and their social, political and ethical implications. There were two main reasons for the introduction of these methodologies: first, we aimed at generating situated forms of ethics, where concerns with nanotechnologies would be entangled with the social, political and cultural "situation" of the participants, instead of being disengaged forms of deliberation; second, we wanted to experiment with alternatives to mainstream participatory mechanisms - instead of limiting these exercises to unending processes of discussion and verbalization, we introduced the possibility of "translating" ethical and social concerns into performances, in such a way that the participants would be able to exchange roles between themselves, generating stronger and more imaginative forms of inter-subjectivity and self-expression.

The initial section of this article reflects on public participation in science and technology, including remarks on nanotechnologies. Afterwards we engage in a theoretical discussion on issues of technology, methodology and intervention in Science and Technology Studies (STS), followed by an explanation of the two methodological innovations that were implemented.

The following section provides an empirical analysis of the participatory mechanism we developed. Some information is offered on the organization of sessions, followed by the main topics that emerged during the discussion and a detailed picture of the performances.

In the discussion, we reflect on how our methodological choices affected the outcome of the focus groups, reflecting on their political aspects, including remarks on the limitations of our exercises and the complexities of our "engaged" approach towards these forms of public participation.

\section{Public Participation in Science and Technology}

In recent years, there has been a major trend in Western democracies to bring sciences to the public, promoting the proliferation of what Callon et al. [8] describe as hybrid forums, including forms of participatory technology assessment such as foresight exercises, scenario workshops and the participatory development of technologies. They involve different forms of what Irwin and Michael [19] call ethno-epistemic assemblages: ways of bringing heterogeneous actors together, allowing innovative configurations of knowledge and practices to open up spaces for the emergence of matters of concern [20] - ways of articulating the cognitive, the ethical and the political in heterogeneous processes characterized by uncertainty.

Unlike what was known within STS as the "deficit model" of the relations between citizens and science based on an asymmetric relation between knowledgeable experts and uninformed publics, addressed through top-down initiatives in science education and popularization - recent approaches to public engagement with science acknowledge the capacity of citizens to draw on their own experiences and capacities to engage in critical and productive ways with scientific knowledge and expertise. This provided the breeding ground for concepts such as "citizen science" and for new forms of public knowledge $[8,18,19]$. These, in turn, have been increasingly regarded as providing relevant contributions to the information and legitimization of decision-making concerning science, technology and expertise, especially those forms 
with more significant implications from the point of view of financial resources and social consequences.

Public Participation in Nanotechnologies:

The DEEPEN Project

Despite the promise of nanotechnologies and the considerable economic investments involved, it is difficult to engage the public regarding the implications of nanotechnological research, and without a visible effort to involve citizens these products could have a low level of acceptance in society, with a consequential retraction from consumers, as with GMOs ([4]: 128). Emerging technologies allow us to explore aspects related to imaginaries, priorities, governance and regulation of science and technology, and public participation in nanotechnology should include a variety of cultural, social and technical perspectives ([22]: 270). As a consequence of the controversies surrounding GMOs, there are now several techniques to involve the public in decision making, such as focus groups, referendums, citizen juries and deliberative mappings ([27]: 21).

A new consensus is emerging, rejecting the old "deficit model", associated with more traditional versions of the public understanding of science, according to which an undifferentiated public, characterized by ignorance, would have to be "educated" by scientists and specialists in order to "understand" science and technology. Consequently, and from 2005 onwards, several exercises on public engagement with nanotechnology have been undertaken, such as citizen juries, consensus conferences and focus groups ([5]: 388). As Hamlett and Cobb recognize, "many theorists call for more robust forms of public involvement that focus on active deliberative practices by ordinary citizens" ([16]: 630), and the aim of some of these new participatory mechanisms is to provide more robust forms of public engagement.

The focus groups organized in Portugal are forms of public participation in science and technology. Since the participants did not have any contact with nanotechnologies, or a very clear notion of what they were, the exercises were not mere compilations of pre-existing concerns, but mechanisms of collective constitution of ethical and social concerns with nanotechnologies. This means that our task, as social scientists, implied explicit forms of intervention to generate matters of concern, raising a set of methodological issues.

\section{Methodology and Intervention: Contextualizing Methodological Innovations}

Some authors suggest that there was a turn to ontology in STS [26,28], illustrating the political role of sociotechnical interventions. The notion of ontological politics, coined by Mol [24], suggests that " $(\ldots)$ reality is manipulated by means of various tools in the course of a diversity of practices" ([24]: 77) - different medical practices enact distinct versions of the body. The normative dimension of interventions was also explored by Callon regarding economic markets. Drawing on the notion of performativity, he argues that economics and the economy co-constitute themselves - the discipline contributes to the framing of economic institutions, such as markets; therefore, the laws of the markets are not in the nature of society or humans - they emerge due to regularities established through actions, including those of economists ([6]: 46-47).

The turn to ontology, reinforcing the performative role of scientific and social interventions, has obvious consequences on how we think about methodology. According to Law, methods multiply reality - they are not mere technical and neutral devices, in fact "[method] is performative. It helps to produce realities. (...) The issue becomes how to make things different, and what to make" ([21]: 143). Along similar lines, Mol suggested that we should think of methods as mediators, actively interfering in the world ([25]: 155), which inevitably transforms the role of social scientists: "Our work, together with the actors, is to multiply possible worlds through collective experimentations and performations" ([7]: 53).

By recognizing that method is neither neutral nor innocent, as social scientists we were aware that our methodological choices would matter, therefore we resorted to two methodologies reflecting broader social and political implications - Freire's and Boal's approaches reflect citizens' experiences of the world, allowing them to become critical and engaged subjects through forms of self-expression that go beyond traditional forms of (verbal) deliberation.

\section{Pedagogy of the Oppressed}

Freire became known worldwide through his innovative and humanist method for adult literacy, initially used in the 1960s in Latin America and later expanded to other parts of the world. He criticized procedures 
dependent on textbooks, involving the mere reproduction of a priori contents, detached from the living experience of students. When treated as "receptors" of information, students become passive recipients, an empty box to be "filled" with "knowledge". He described this type of education as banking education.

Freire advocated the critical questioning of daily life and experience through a process he labelled as "conscientization" (critical consciousness) - the "process through which human beings are critically part of the transforming action" ([13]: 131). The learner shares with the teacher knowledge that is not available to the former, requiring a suspension of the traditional teacher/student asymmetry. The production of knowledge becomes a shared and dialogical process.

The starting point of his method is the life world of students ([12]: 112-122). A set of generative words are chosen to start the process, selected from the students' daily vocabulary, taking into account aspects such as phonetic richness or even their potential for social, cultural and political engagement. Specific existential situations, illustrating concrete problems, are formulated through the use of generative words - the particular experiences of students are considered relevant.

\section{Theatre of the Oppressed}

The second methodological innovation concerned the introduction of elements of the Theatre of the Oppressed, as conceived by the Brazilian playwright Augusto Boal, consisting of a set of procedures that aim at identifying and solving problematic social and personal situations. It seeks to recover the "original spirit of art", as a form of building common experiences envisioning liberation and emancipation ([1]: 119). Oppression is defined in a broad way, including social, political, cognitive or personal forms of limiting or suppressing the capacity for expression and action. Practically, this comprises two aspects: 1) the spectator acts again (becoming a spect-actor); 2) the property of characters by "professional" individual actors is broken (ibid: 123). The spectator returns to the stage, acquiring agency in such a way that others in the same situation can identify and become actively involved in the theatrical performance, preparing themselves for action in the "real" world (ibid: 122).

Different forms have been developed ([3]:3), but the most popular one is called "Forum Theatre". It begins with the narration of a social/political problem with a difficult solution, followed by a performance illustrating the problem and a possible outcome, usually reproducing the initial state of oppression ([1]: 139) and the text should allow spect-actors to identify the views of each character.

By the end of the presentation, the participants are asked if they agree with the solution. A negative answer will allow a re-enactment. Every criticism should be enacted, rather than verbally formulated, through the replacement of the characters and a replaying of the original presentation. The outcome will be a confrontation between possible solutions - those from the initial group of performers and those from the spect-actors, replaying the performance, opening up the space for deliberation. One of the initial performers, or someone offstage, takes a key role in this process, that of the Joker, explaining the rules of the game, correcting procedural mistakes and encouraging the participation of spect-actors ([2]:243). The forum should finish with a presentation, prepared by the spect-actors, of a "model of action for the future" (ibid: 245).

The following example took place in Chombote, Peru, during the 1970s ([1]: 139-141). It concerned a young man who was forced by his boss to work twelve consecutive hours every day at a fish meals factory. The "problem" that the Forum Theatre addressed was how to fight labour exploitation. The young man thought that the solution was to fill the machine with excessive fish, thus breaking it; while it was being fixed, all the workers could rest.

The scene was initially stated by the actors, who represented the workers, the boss and the foreman, and the stage resembled the fish meals factory. They were discussing a solution to the problem and followed the initial solution given by the young man, thus overloading the machine and breaking it, giving the workers a couple of hours to relax. After the scene was staged, the audience (the factory workers) was asked if this was the best solution, and the answer was no. Afterwards, the Theatre Forum technique was applied - different spect-actors were brought to the stage and replaced the actor portraying the young man, re-enacting different responses. The first two solutions consisted of destroying the factory (through a bomb) and going on strike. In both cases, the participants realized that these outcomes were not good enough - if the factory was destroyed, they would become unemployed, and going on strike would mean that the boss could find new workers to replace them, due to the high unemployment rate. 
The third and final solution was the constitution of a union to negotiate workers' demands, setting up mutual funds and improving work conditions. All the participants considered this to be the best decision, providing them with a good model for future action.

\section{The Focus Groups}

Organization

After presenting the theoretical background and the methodological innovations, we now explain how these focus groups took place. Two sets of sessions were organized, each one composed of two separate sessions. The participants met at the Centre for Social Studies of the University of Coimbra, a well known Research Centre in Social Sciences. A third session involving both groups was then set up, and each group of participants was asked to prepare a performance where their concerns, questions and responses were made available to the other group. This was followed by discussion, depending on the various performative settings

Four groups of participants were constituted on the basis of their commitment to specific concerns which were expected to be relevant for their stances towards nanotechnologies. The groups were paired so that their concerns and commitments "mirrored" each other each pair of groups included a "concerned" and a "stranger" group. The "concerned" group was constituted of participants linked to associations, organizations or movements with some stake in issues which are expected to be significantly affected by nanotechnologies. The "stranger" group was composed of participants who did not have permanent commitments to organizations or movements - they participated as individual citizens engaged in activities/practices likely to be affected by nanotechnologies.

The sessions involving each of the groups separately started with a general introduction to the DEEPEN project and its goals. Besides the participants, four members of the research project were present (two of them working as moderators/facilitators, and two research assistants providing support). Afterwards, three slides (containing news articles and general information on nanotechnology, its applications, potential benefits and dangers) were projected on: a) definitions and concepts of nanotechnology; b) nanotechnology today; and c) the future of nanotechnology. This was followed by a discussion of each slide which then moved towards a general discussion where participants were encouraged to draw on their experiences (following Freire's approach) to think through the problems and potentialities of nanotechnology. This first session took place on a weekday. Before the session, participants were handed some information on nanotechnology. Throughout the session, one member of the team took extensive notes of the debate in order to capture some of the "strong" statements and ideas emerging. After the discussion, these highlights were used to identify the main topics for the organization of the performance.

The sessions reserved for the performances were held during the weekend. After a brief overview, participants discussed the key issues arising from the previous meeting. They would then choose one or several topics to be presented to the other group in the form of a performance. At this stage, they were left alone for most of the time to develop their performances, after being instructed on the forum theatre technique. Participants were required to draft a story or script and to develop it into a presentation.

In the first week, the sessions involved national leaders from patient/health organizations (including two physicians), very close to the biomedical paradigm, and a group of practitioners of activities associated with the promotion of the "natural" body and healthy life styles, including a yoga teacher, a vegan, a laughter yoga therapist and a practitioner of homeopathy and Reiki. The members of the group advocating the biomedical paradigm were selected based on a list of contacts from another research project on patient organizations, and the "stranger group" was constituted after calling several alternative and complementary medicine clinics, including Yoga and Reiki centres.

In the second week, the "concerned" group included leaders of environmental, social justice and local action groups, and most of them were representatives of their associations in Coimbra. The "stranger" group combined two sub-groups: the first was associated with principles of autonomy and agency - we identified well-known figures in Portuguese society, such as union leaders, scholars with a background in bioethics, or charismatic figures in education. The other sub-group was composed of confident believers, selected after conducting a survey with 60 random subjects, using 17 questions inspired by a questionnaire from the Wellcome Trust Institute in the UK. Participants identified as confident believers or 
characterized by autonomy and agency were brought together as one group. On that weekend, again, two parallel sessions were held to allow groups to prepare their performances and, in the afternoon, these were consecutively run. All the sessions were recorded through audio and video devices, and the audio files were transcribed.

The fact that we selected the participants according to specific stances, political attitudes and life choices can generate concerns, and Hamlett and Cobb recognize that some problems can arise when advocacy groups are "called" to participate in deliberative procedures. As the authors suggest:

"Reliance upon organized advocacy groups to express public opinion falls prey to the politically strategic manoeuvrings of interest-group bargaining. Missing from the political mix is the voice of informed, deliberative citizens who are not already committed to a specific policy outcome" ([16]: 630).

In the case of our exercises, we had collectives that included members of patient organizations or social action groups, and "situated" approaches to ethical and social concerns and imaginaries of nanotechnologies were supported by these a priori associations. Instead of seeking relatively detached and abstract ethical and social statements, following traditional approaches to deliberation, our goal was actually to use the life world, concerns and contexts of the participants as filtering mechanisms, leading to their "conscientization". Therefore, the fact that some of these groups had members sharing certain a priori social and political concerns was fundamental in order to conduct the exercise.

\section{Themes from the Focus Groups}

There were seven topics that cut across all groups: the novelty regarding the dimensions of nanotechnology; pollution and other environmental concerns, with inputs from the history of other technologies; impacts on human health, namely concerns with medium- and long-term side effects; inequalities in access to the technologies, at national and international levels; issues concerning the access to information; concerns with regulation and legislation; issues dealing with control - a set of narratives was produced offering views either of the control of humans by nanotechnology or of the use of nanotechnology to provide more pleasure or benefits for humans.
Regarding specific issues that emerged in each of the groups, in group I, aspects such as informed consent, doctor-patient relationships and the definition of nanotechnology arose as prominent. Within group II, the issue arose of the possibility that nanotechnological advances might jeopardize the very existence of alternative or complementary medicines. They also believed that children should be regarded as potential actors in participatory processes.

Regarding group III, two specific issues stood out: the direct relationship between technology and wars for the control of resources and a direct attempt to connect nanotechnology with social issues. In group $\mathrm{IV}$, there was a lively discussion on the social and civic responsibility of scientists.

Some of these issues can emerge during public discussions on nanotechnology $([9,23])$. We should also note that Hamlett et al.'s conclusions apply to our focus groups. By going through some of the matters of concern that arose, we agree that:

"Issues of economics, equal access and equity are important, as are technological impact on personal freedom, civil rights, and political rights. Ordinary people have a fairly nuanced and sophisticated view of the role of new technologies in their everyday lives and in society at large" ([17]: 12).

However, we should note that our goal was not a mere discussion of ethical and social concerns, but their transformation into performances, hoping that this would permit a more robust engagement and empowerment of participants, as well as an opportunity to share different perceptions, beyond the framework of verbal discussion.

The Creative Presentations and Performances

\section{Group I (Patient Organizations)}

Group I simulated an Ethics Committee. One participant made an introduction, explaining the difficulty of treating colorectal cancer, the low life expectancy it causes and the side-effects of the treatments. The Ethics Committee would discuss the emerging questions and ethical and social issues linked to a new nanotechnology-based treatment (permitting the application of localized chemotherapy, not harming healthy tissues and organs). Then, another member intervened, praising the therapy and its advantages over conventional chemotherapy, suggesting that no special regulation 
was necessary. Existing regulatory mechanisms, currently used for clinical trials, were perfectly acceptable, adding that all phases of research had been concluded, thus the way was open for testing the therapy on human subjects.

Another member took a contrary position - he was against the introduction of the nano-based therapy. He drew on a range of arguments, such as ignorance of longterm effects, lack of information on whether the animal models were adequate for extrapolation of results to humans, absence of effective controls, compounded by the fact that patient organizations were not part of control mechanisms, stating possible problems with pollution and even terrorism.

The last intervention was by the Chairman of the Ethics Committee. Agreeing that nanotechnology is revolutionary, he added that it could mean an improvement but also the destruction of mankind. His greatest concerns were prejudicial uses, so the remedy would be to act wisely. The selected scenario provided a setting familiar to all participants of this group, either physicians or members of ethical committees of patient associations.

\section{Group II (Alternative and Complementary Practices)}

Group II presented a sketch where a child/scientist who discovered nanotechnology offered it to different people. Nanotechnology was presented as a box with many toys inside (benefits and applications of nanotechnology). The Reiki practitioner played a child who wanted to be a superman, the vegan represented consumers and the Yoga teacher impersonated a famous doctor.

Initially the Laughter Yoga therapist presented the benefits of nanotechnology -ending wars, famine, disease or suffering, stating some benefits for the consumer. Then she took an artefact - a duct tape - from the box and handed it to the vegan.

The vegan/consumer enumerated negative aspects the food would not be natural, the flavour and nutrients would be altered, it would be unhealthy. The Laughter Yoga therapist took back the duct tape, asked the vegan how much nano she wanted and cut a little bit.

The Laughter Yoga therapist/child scientist then turned to the Reiki practitioner, stating that nanotechnology could bring him many benefits, since he was being bullied. Thanks to nanotechnology, this child could become a superhero, increasing his physical strength, thus winning any fight. She then evoked the military applications of nanotechnology - bulletproof boots and the capacity for reading the enemy's mind. This time, the artefact coming out of her box was a nano lollypop, a very powerful weapon. The Reiki practitioner stated that nanotechnology could fall into the wrong hands - the nano lollypop was a very dangerous toy, and he threw it back in the box.

The last gift was for the famous doctor. The child scientist enumerated some benefits for medicine DNA manipulation to create perfect children; elimination of existing diseases; creating organs from scratch; adapting the human body to pollution. The Yoga teacher stated that important achievements could be reached, such as eliminating noxious bacteria or improving breathing. He added, however, that since the technology would not always be available and could create dependence, he would propose a different approach. He invited everyone to engage in a breathing exercise, illustrating different ways of feeling and dealing with the body.

In the end, the Laughter Yoga therapist presented four recommendations designed as precautionary projects: i) a global programme of education and training on nano for children, including artistic resources; ii) the creation of centres for the conservation of life forms (DNA banks) before their expected transformations through nanotechnologies; iii) a project of participation and citizenship allowing citizens to control the way their tax-money is applied; and iv) a project to raise intercultural awareness for nano-enactors and decision-makers.

\section{Group III (Environmental, Social Justice and Local Action Groups)}

Group III presented a parody of a famous Portuguese TV show. The format of the show is a debate on a "hot" topic opposing two groups of invited speakers, with interventions from a studio audience. For the presentation, four members of the group played the panel speakers, one the moderator and three acted as audience members. After an introduction by the moderator, who asked whether nanotechnology could save humankind, a participant presented his arguments for the promotion of the military uses of nanotechnology: there are enemies of democracy; it is necessary to have effective defence programs, to protect the population and to have intelligence services. He recalled that nuclear weapons 
were responsible for 60 years of world peace - military applications were beneficial to populations. During his speech, he was interrupted by the audience members, who objected to his arguments, fearing for the freedom of citizens and the interference of intelligence services in their lives.

Then, another participant spoke about the benefits of nano for health - better and faster diagnoses, smaller devices to scan patients and cheaper treatments, giving as examples the diagnosis and treatment of cancer. The members of the audience focused on concerns over access and the invasive character of nanotechnology.

Another member, acting as the representative of the Iberian Institute for Nanotechnology, chose to address the concerns of the audience and stated that people should trust science; nanotechnology would benefit mankind, boosting quality of life; it would be cheap and nanorobots would be within the reach of everyone. The audience was mainly concerned about social imbalances and the replacement of people by machines.

The final speaker argued that nanotechnology was beneficial to the environment. Environmental problems would disappear; there would be fresh water for everyone, and thus no more wars for the control of that resource; waste, energy consumption and resource exploitation would be reduced. The audience members expressed their concerns, namely how clean the new technologies would be and whether they would produce reactive garbage.

Instead of presenting a formal set of recommendations, the group saved a part of their presentation for questions from the audience. The audience was meant to be representative of the "public", whereas the speakers stood for the "establishment", those with the capacity to make decisions.

\section{Group IV (Confident Believers + Autonomy and Agency)}

Group IV recreated the myths of Pandora and Prometheus. The narrator started by reading a text telling the story of Prometheus and how he stole fire from the Gods. Since it was guarded and inaccessible, stealing it meant that mankind would have access to that fire/knowledge.

This was followed by a participant playing Prometheus, reading paper slips with questions such as "What if we had eternal life?", "What if there was no more famine?" He then handed the slips to the audience, took a torch (representing fire) and went on to read and then handed over to the audience another set of paper slips stating the benefits of nanotechnology.

After Prometheus, the narrator moved to the myth of Pandora, understood as a revenge of the gods, who gave her a box full of evil and risks. As the narrator was referring to the opening of the mythological box, two other members opened a box, full of what the narrator called "all the dangers that stalk us" - famine, disease, death or environmental disaster. Pandora started drawing red papers from it, reading and handing them over to the audience - "What if it is used out of control?", "I don't know...I'm afraid", "Lethal Weapons", "New Forms of Pollution", "Surveillance abuses", "De-humanization."

After removing all the papers from the Box, Pandora showed what was left, a word written in the bottom - "Anti-Hope", a clue for the next intervention of the narrator:

"Today we still live between Prometheus and Pandora, between audacity, the thirst for knowledge, the will to know, on the one hand, and the threat of disaster, the fear of catastrophe, the fear of annihilation, the suspicion towards science on the other hand. But, of all the evils of Pandora's box, one and only one remained in the box. And it was not dispersed throughout Earth: the one which would destroy hope."

At this point, a screen, set at the beginning, and separating the two groups (Prometheus's and Pandora's) was removed, representing the removal of barriers between risks and benefits and between scientists and lay people, illustrating how these dimensions are linked. Then, another group member, stating that hope was all there was left, provided some recommendations, such as the creation of a discussion forum where decision-makers, scientists and stakeholders could participate.

\section{Discussion}

What most of these participants had in common was their apparent "ignorance" towards nanotechnologies. The goal of the focus groups was not the mere listing of ethical and social concerns, but the "empowerment" or "education" of participants, allowing them to develop what Freire designated as "conscientization". This awareness towards potential impacts of nanotechnologies was recruited 
through the application of the Forum Theatre techniques, and the four groups transformed their ethical and social concerns into theatrical performances, followed by a period of discussion, allowing the exchange of roles for the re-enactment of the play, depending on the different approaches of each group.

Different performances were developed, transforming conceptions of nanotechnologies into dramaturgical processes. These presentations were active forms of imagining possible futures and collective political, social and ethical responses to nanotechnologies. Instead of merely discussing hypothetical visions or futures, the participants were able to articulate different socio-technological scenarios: they mediated their ethical relationship with nanotechnologies through their specific situation in the world (as members of a patient organizations or local action groups); they questioned their own situation in the world by discussing with other individuals and also by including diverse ideological, social and ethical positions in their final performance; they "educated" the members of the research team, by preparing performances that were quite complex, indicating forms of expertise beyond the usual repertoire of social sciences.

After these initial remarks, we should now provide a more rigorous analysis of how issues of methodology and intervention contributed to these outcomes.

\section{Focus Groups, Methodology and Intervention}

Having in mind these exercises of public participation in science and technology, how should we think about the role of the research team in constituting these "engaged subjectivities" with nanotechnology?

First of all, the research team recognized the political aspects regarding the design and conduction of these participatory exercises. What was at stake was not merely identifying ethical and social statements on nanotechnologies, but constituting participatory and engaged subjects through various actions. In some cases, we discovered (after inviting again some of the participants for another exercise, a deliberative forum on Nanotechnologies) that, after attending the focus groups, they became highly interested in the topic, and one of them decided to set up a website to release information on the potential negative impacts of nano.

The methodology reflected the Pedagogy of the Oppressed of Freire, therefore the emergence of concerns with nanotechnologies was mediated through elements of the daily life of these participants. What was at stake was not a mere "banking education" - where the participants should "learn" what nanotechnologies were, having then to respond with a set of decontextualized and abstract statements about their potential implications but a process of co-constitution of knowledge. The organizers of the participatory event witnessed the complexity of the participants' life through a multiplicity of images, ideas and performances of a different future, conditioned by nanotechnologies.

By participating in the event, these citizens became concerned with nanotechnologies. They became participatory actors because they were part of a sociotechnical network composed of methodologies, new types of knowledge, a specific physical space and expectations regarding what they should produce. The reflections of Foucault on discipline [10] illustrate how subjectivity is fabricated in institutional spaces. In this case, the laboratory of social sciences transformed citizens not aware of nanotechnologies into subjects with the ability to articulate ethical and social concerns on these emerging technologies, entangling them with their everyday life experiences and presenting them through the performative resources developed by Boal.

In order to perform participatory subjectivities, the moderators had to intervene through various ways: we projected slides containing information on nanotechnologies; we interpellated the participants on the potential impacts over their lives, "performing" their identities through speech acts; we explained how their final presentations should be organized; we placed individuals in groups with specific titles, contributing towards the formation of a collective spirit leading to the creation of "teams" [14]; we wrote down the main ideas resulting from the discussions, reading them one by one, "strengthening" their representations of nanotechnologies. These different forms of agency illustrate the central role undertaken by the research team that, through the "facilitation" of the exercise, allowed the emergence of the concerned individual through choices leading to different politics of participatory subjectivities.

These exercises are also interesting to explore different forms of agency in participatory devices. Initially we could attribute agency exclusively to the methodological and disciplinary intentionality of the research team, that is "making up" [15] these participants in several ways. However, we believe that it is more correct to interpret these processes as collaborative. Firstly, these participants are not passive subjects. The methodological 
approach, that values epistemological symmetry, avoids a mere "banking" conception of the subjects. These subjects contribute with their particular knowledge as activists, medical doctors or promoters of complementary therapies - and "negotiate" through the most varied ways with the research team. These negotiations can assume several forms: discussions on how to conduct the performance, involving deliberations about the final format and its correspondence with the initial expectations; requests for certain materials to construct artefacts included in the final performance (such as the Pandora box or cards with statements on dangers and promises of nanotechnologies); the request for the noninterference of the research team during the design of the performance - the group composed of supporters of alternative and complementary therapies asked the researchers to abandon the room, in order to concentrate on the task at hand. Since we were not dealing with passive subjects, our "agency" as researchers was limited - although an important part of Boal's Theatre Forum involves the exchange of roles, engaging the "spectactors" in the play, in our focus groups we did not witness this phenomenon, and although we suggested that possibility, it was only discussed and never reenacted.

An essential aspect to consider concerns the negotiations between group members. The final performances involved discussing, arguing, synthesizing different perspectives and attempting to reach consensus. If our methodological concerns reflect issues of power and knowledge, we should not ignore that within the group discussion (when the researchers were away) some inequalities were also present, depending on the diverse rhetorical, argumentative and psychological dispositions of the participants. In some cases, one or two participants were "in charge" of assessing the various proposals generated by the group (due to their status, past experience with similar events, the dominant role they progressively acquired during the discussions or their availability to engage in the exercise). In another case, one of the groups was unable to reach a binding decision, and the intervention of the moderator was decisive to determine their performance - the researcher summarized various positions, suggesting a solution that was immediately accepted by the participants. In other cases, the discussions between elements seemed almost endless, and the inability to reach a consensus demanded them to "rush" towards a conclusion, finding a solution that summarized different possibilities.
Participatory Subjectivities

We have analyzed various aspects linked to the emergence of participatory subjects. However, how can we reflect on these emerging subjectivities? What kind of participatory subject is this?

The reflections of Foucault on technologies of the self [11] allow us to face these practices of formation and maintenance of subjectivity as a form of ethical "equipment" that can be applied in various circumstances of daily life. In the case of the focus groups, how can we reflect on this ethical equipment? Should we consider this participatory exercise as promoting what Freire designated as the conscientized subject, where, through a dialogist and symmetrical approach to literacy, individuals develop critical consciousness according to their social contexts?

These focus groups allowed the emergence of ethical and social concerns on a technology whose most promising applications are still experimental. In this case, we face a "conscientization" directed towards the future, and the participants articulated their concerns under the aegis of their specific situation in the world - as activists, members of patient organizations, supporters of alternative therapies, and so on. The citizens did not participate as mere recipients to be "informed" with vague notions of nanotechnologies, but as "situated" members according to different collectives that shaped their ethical and social concerns. The relationship between participatory subjectivities and this new world is mediated by different aspects: rhetorical and performative "capacities"; former experience with technologies; the willingness to participate and engage in the exercise; methodological and institutional frameworks that "conditioned" their possibilities for self-expression; expectations or even their willingness to transport this experience to daily interactions, allowing others to become familiarized with the various aspects at stake.

If our methodological ambitions aimed at creating a certain degree of "conscientization", allowing robust forms of situated interaction with nanotechnologies, how should we interpret these focus groups, since most of these objects (namely the revolutionary nanotechnological applications) belong to a future that has not arrived yet?

We believe that the transformation of the life world of the participants operated along two axes. First, the space of participation was designed in order to be influenced by the agency of the participants and their 
situatedness - instead of being a disciplinary device with a limited or univocal focus of agency, it permitted diverse interactions that transformed the design of the "participatory institution" and the possible results of action - citizens were able to construct their own visions of nanotechnologies, selecting the performances of their choice and proposing solutions that arose from their discussions. Second, by participating in the exercise, the participants were "empowered" with new information, performative and argumentative skills that will allow them, in the future, to become engaged in a world influenced by nanotechnologies. These plans of action for the future cannot be controlled by the research team or the institution their choices, the future development of nanotechnologies and the binding nature of the imagined future worlds will assess the "efficiency" of the focus groups.

\section{Limitations}

Although we believe that these forms of participation managed to "empower" participants, partially due to the format of the focus groups, we should also address some of the limitations of the exercise, illustrating the complexities involving issues of methodology and intervention.

First of all, we should think about the limits of our intervention as social scientists. We were not able to scrupulously follow the "scripts" proposed by Freire and Boal, and some aspects (such as the replacement of actors and the re-enactment of the presentation, or the use of "generative words", replacing the slides on nanotechnology by more specific and precise articulations between these emerging technologies and the specific world of each group) did not take place. In this case, the attempt to introduce those features would imply an increasing "control" by the facilitators, jeopardizing the symmetry ambitioned by Freire and Boal. The fact that the participants could actually display their agency prevented us from applying the "innovations" in detail, but also allowed citizens to reinvent possible scenarios for intervention. In one case, they actually managed to involve everyone in the room in a collective exercise of relaxation (as well as Laughter Yoga), due to the open format of the exercise.

Secondly, as part of our attempt to avoid some traditional forms of deliberation, drawing on the exclusive use of the rational argument (sometimes detached from everyday life and the social/ethical/cultural/political situation of citizens) we explicitly sought the formation of situated ethics and subjectivities, through the help of two "innovations". In order to do so, we were also responsible for the formation of groups that reflected that same "idealized" situatedness. Although this process of selection was not arbitrary, we should not naturalize group identities as if they existed before the participatory device. If we were looking for situated ethical and social concerns, we were also (partially) responsible for the creation of those representations, by focusing on certain aspects of the life world of the participants and inevitably ignoring other dimensions of their existence. This is a complex issue that deals with problems of political representation and collectives - although we can understand group identities as a "construction" (involving various forms of negotiation), nevertheless these exercises allowed the participants to overcome mere individual concerns, engaging with others in the creation of possibilities for a different world.

Thirdly, although some of the participants also attended a deliberative forum some months afterwards (addressing some of the impacts of the focus group), we did not have the chance to effectively assess the impact of the focus groups on their lives. We know that some of them became engaged, they shared their experiences with family members and co-workers (as previously mentioned, a participant decided to set up a website compiling information on possible dangers of nanotechnologies). We witnessed the development of their concerns and ethicalities throughout the focus groups, but if the aim of these devices was to promote forms of "conscientization", the deployment of various mechanisms, before and after the exercise, could be justified, involving for instance surveys or interviews and requiring a set of follow-up devices. This would involve various actors, such as funding agencies, research institutes and the participants themselves.

\section{Conclusion}

Despite the above mentioned limitations, our focus groups strengthen the assumption that the role of social scientists is crucial concerning the outcomes of participatory devices. Therefore, we believe that more attention should be dedicated to the complexities involving public participation and methodology instead of naturalizing some of the results as mere reflections of the participants" "will" and "agency", 
perhaps there should be more discussion on the politics of those mechanisms, including the possibility of introducing new and innovative methodologies that expand the chances for self-expression, empowerment and public engagement of the participants.

Through the analysis of these focus groups, we have elucidated the political aspects of a specific mechanism of public participation, since the creation and public presentation of concerns with nanotechnology was mediated by various forms of sociological intervention. We believe that the methodology we selected was able to provide a more robust and substantial engagement of the participants, compared to other traditional forms of deliberation that depend on the exclusive use of the rational argument or on the top down "education" of the participants on scientific issues. As a recommendation, we believe that further exercises of participation (including those dealing with nanotechnologies) should include participatory ways of controlling their design, allowing participants to resort to a broad array of methodological mechanisms reflecting their cultural, ethnic, political, social and ethical contexts, thus allowing more imaginative, creative and engaging forms of public involvement.

Acknowledgments This paper is based on research carried out within the Project DEEPEN (Deepening Ethical Engagement and Participation in Emerging Nanotechnologies), funded by the Science and Society Program, 6th Framework Program, European Commission (Project nr. 036719). While gratefully acknowledging the contribution of other research team members to their reflection, the authors are solely responsible for the views, as well as for the flaws, errors or omissions, contained in this paper.

\section{References}

1. Boal A (1979) Theatre of the Oppressed. Pluto Press, London

2. Boal A (1992) Games for Actors and Non-Actors. Routledge, London and New York

3. Boal A (2006) The Aesthetics of the Oppressed. Routledge, London and New York

4. Bowman D, Hodge G (2007) Nanotechnology and Public Interest Dialogue. Some International Observations. Bull Sci Technol Soc 27(2):118-132

5. Burri R, Bellucci S (2008) Public perception of nanotechnology. J Nanopart Res 10(3):387-391

6. Callon M (1998) The laws of the markets. Blackwell, Oxford

7. Callon M (2006) What does it mean to say that economics is performative? CSI Working Papers Series, 5. Retrieved
December 24, 2012, from http://halshs.archives-ouvertes.fr/ docs/00/09/15/96/PDF/WP_CSI_005.pdf

8. Callon M, Lascoumes P, Barthe Y (2001) Agir dans un monde incertain - essai sur la démocratie technique. Éditions du seuil, Paris

9. Ebbesen M, Andersen S, Besenbacher F (2006) Ethics in Nanotechnology: starting from scratch? Bulletin of science. Technol Soc 26(6):451-462

10. Foucault M (1995) Discipline and punish. Vintage Books, New York

11. Foucault M (2006) The Hermeneutics of the Subject - Lectures at the Collège de France 1981-1982. Picador, New York

12. Freire P (1967) Educação Como Prática da Liberdade [Education as a Practice of Freedom]. (Rio de Janeiro: Paz e Terra)

13. Freire P (1977) Acção cultural para a libertação e outros escritos [Cultural action for liberation and other writings]. Moraes editors, Lisbon

14. Goffman E (1969) The presentation of self in everyday life. Penguin, London

15. Hacking I (2002) Historical Ontology. Harvard University Press, Cambridge

16. Hamlett P, Cobb M (2006) Potential solutions to public deliberation problems: structured deliberations and polarization cascades. Policy Stud J 34(4):629-648

17. Hamlett P, Cobb M, Guston D (2008) National Citizens Technology Forum: Nanotechnologies and Human Enhancement. CNS-ASU Report \#R08-0003. Center for Nanotechnology in Society, Arizona State University, Tempe, AZ. Retrieved December 24, 2012, from http://cns.asu.edu/ files/report_NCTF-Summary-Report-final-format.pdf

18. Irwin A (1995) Citizen science. Routledge, London and New York

19. Irwin A, Michael M (2003) Science, social theory and public knowledge. Open University Press, Maidenhead

20. Latour B (2004) Politics of Nature. Harvard University Press, Cambridge

21. Law J (2004) After method - mess in social science research. Routledge, London and New York

22. Macnaghten P, Kearnes M, Wynne B (2005) Nanotechnology, governance, and public deliberation: What role for the social sciences? Sci Commun 27(2):268-291

23. Macoubrie J (2006) Nanotechnology: public concerns, reasoning and trust in government. Public Understand Sci 15 (2):221-241

24. Mol A (1999) Ontological politics. A word and some questions. In: Law J, Hassard J (eds) Actor network theory and after. Blackwell, Oxford, pp 74-90

25. Mol A (2002) The body multiple: ontology in medical practice. Duke University Press, Durham

26. van Heuer B, Leydesdorff L, Wyatt S (2013) Turning to ontology in STS? Turning to STS through 'Ontology'. Social studies of science (in press). doi:10.1177/0306312712458144

27. Wilsdon J (2004) The politics of small things: nanotechnology, risk, and uncertainty. IEEE Technology and Society Magazine. Winter 2004:16-21

28. Woolgar S, Cheniti T, Lezaun J, Neyland D, Sugden C, Toennesen C (2008, June). A turn to ontology in STS? (Paper presented at the workshop "A Turn To Ontology", University of Oxford) 